serious sequelae. There appears potential to improve chlamydia testing cost-effectiveness by increasing PN.

\section{P195 SHOULD MALE CIRCUMCISION BE CONSIDERED CURATIVE TREATMENT FOR LICHEN SCLEROSUS?}

${ }^{1}$ Farai Nyatsanza*, ${ }^{2}$ Benedict Holden. ${ }^{1}$ Imperial College Healthcare Trust, London, UK; ${ }^{2}$ Hillingdon Hospital, London, UK

\subsection{6/sextrans-2015-052126.239}

Lichen Sclerosus is a chronic inflammatory skin disorder. In men it presents mainly on the prepuce, coronal sulcus and glans penis. The cause of lichen sclerosus is not fully understood, but genetic and autoimmune factors are thought to be important. Infections have been investigated as a cause, but with no clear evidence of a potential causative agent. In men the association with autoimmune diseases is weaker; however studies have shown a family history of diabetes mellitus, and thyroid disease are possible risk factors. Other suggested potential causes are chronic intermittent damage by urine, as early circumcision seems to be preventative in those who do not have congenital anomalies such as hypospadias.

Recommended treatments include circumcision and potent topical steroid ointments. Taking this into consideration we reviewed notes of patients that presented to the monthly Joint Dermatology clinic with a diagnosis of lichen sclerosus to ascertain the number of recurrences post circumcision.

We found four cases of recurrence of lichen sclerosus in patients attending the clinic over a four month period. Ages varied between 39-81 years old. One patient had diabetes mellitus, and another had been circumcised twice. All patients needed treatment with potent topical steroid ointment. Lipscombe et al. stated that $50 \%$ of patients who had a circumcision had a recurrence. It is important when discussing management with patients to remember that lichen sclerosus can recur after circumcision. From our observations, the presence of folds of skin still covering the glans penis best predicts recurrence.

\section{P196 VULNERABILITY FACTORS IN VICTIMS OF SEXUAL ASSAULT PRESENTING TO A RURAL SEXUAL HEALTH CLINIC}

Helen Martin, Amy Pearce, Frances Keane, George Morris*. Sexual Health Hub, Royal Cornwall Hospital, Truro, Cornwall, UK

\subsection{6/sextrans-2015-052126.240}

Background/introduction The Office for National Statistics show that $1 / 5$ of women and 1/40 men over 16 years report having been a victim of sexual assault (SA).

Aim(s)/objectives To identify vulnerability factors (VFs) including alcohol/substance misuse and mental health conditions, in patients presenting as a direct result of a SA or who disclose a previous SA during a routine consultation.

Methods Retrospective notes review of 2 patient groups to identify VF disclosure;

1. All new presentations during a 2 week period disclosing previous SA during their consultation.

2. All presentations to sexual health over a 3 month period directly related to a SA.

Results Group 1: 291 attendances. 19 (6.5\%) (16 female, 3 male) disclosed previous a SA, 3 were $<18$ yrs.
Group 2: 34 attendances (32 females, 2 males) aged 13-61 years ( 8 were $<18$ years). Those with VFs are shown in the table below.

\begin{tabular}{lll} 
Abstract P196 Table 1 & Vulnerability factors for sexual assault \\
\hline Vulnerability Factors (VF) & \multicolumn{2}{c}{ Number of Patients (\%) } \\
\hline High Alcohol Intake & Group 1 & Group 2 \\
Recreational Drug Use & $5(26)$ & $10(29)$ \\
Previous Sexual Assault & $5(26)$ & $5(15)$ \\
Previous Domestic Violence & $\mathrm{n} / \mathrm{a}$ & $11(32)$ \\
Known to Social Services & Not Available & $5(15)$ \\
Looked after Child & $3(16)$ & $12(35)$ \\
Vulnerable Adult & $2(11)$ & $2(6)$ \\
Mental Health Condition & $3(16)$ & $6(18)$ \\
Patients with 2 or more VFs & $7(37)$ & $20(59)$ \\
\hline
\end{tabular}

Discussion/conclusion Over $50 \%$ of patients had 2 or more identifiable VFs. Increasing staff awareness of VFs and improving links with support services may help to reduce the risk of sexual assault in vulnerable groups by allowing earlier identification of those at risk.

\section{P197 DOWN WITH THE KIDS - ARE WE DOING ENOUGH TO PROVIDE A HOLISTIC SEXUAL HEALTH SERVICE TO VULNERABLE YOUNG PEOPLE?}

Susanna Currie*, Annie Houldey, Chris Ward, Vincent Lee. Manchester Royal Infirmary, Manchester, UK

\subsection{6/sextrans-2015-052126.241}

Background/introduction The sexual health of young people in the UK is amongst the worst in Europe, with high prevalence of sexually transmitted infections (STIs) and unwanted pregnancies. Although most are involved in consensual sexual activity, they may also be victims of sexual abuse or exploitation, usually unrecognised by themselves or health care professionals.

We have developed a proforma based on the BASHH young persons' proforma for patients under 18 attending the service which includes safe guarding issues.

Aim(s)/objectives To review the management of young persons' sexual health in an inner city sexual health clinic.

Methods Retrospective case note review of all patients $<18$ years attending clinic in 2012 and 2013.

Results 93 patients were identified; 34 (36.6\%) were $<16$ years (7 M; 27F); median age 15 years (range 11-15). 32 (94.1\%) were sexually active; all (100\%) of which accepted STI screening. $14(45.2 \%)$ tested positive for at least one STI. The proforma was completed for 33 (97.1\%) patients.

$14(41.2 \%)$ of the patients had contact with social services; 10 (29.4\%) had non-consensual sexual activity; 15 (44.1\%) had mental health issues and 4 (11.8\%) used recreational drugs. All of them have been followed up according to local guidelines.

Conclusion The proforma enables us to identify those with safeguarding issues and STIs. An appropriate safeguarding referral pathway and local multi-agency arrangements are in place to help and protect these young people. Further education and communication are needed to raise the awareness and improve the sexual health and wellbeing of the young people. 